\title{
Kronik Obstrüktif Akciğer Hastalığı olan bireylerin yeti yitimi, anksiyete ve depresyon yönünden değerlendirilmesi
}

\author{
Evaluation of individuals with Chronic Obstructive Pulmonary Disease in terms \\ of disability, anxiety and depression
}

\author{
Bilgen Begüm Afşar*, Murat Yalçınsoy, Halil İbrahim Yakar, Sevinç Bilgin, Esen \\ Akkaya \\ Göğüs Hastalıkları Kliniği (Dr. B. B. Afşar), Uzun Mehmet Gögüs ve Meslek Hastalıkları \\ Hastanesi, TR-67020 Zonguldak, Göğüs Hastalıkları Kliniği (Dr. M. Yalçınsoy, Dr. H. İ. Yakar, \\ Dr. S. Bilgin, Dr. E. Akkaya), Süreyya Paşa Göğüs Hastalıkları ve Göğüs Cerrahisi Eğitim ve \\ Araştırma Hastanesi, TR-34844 İstanbul
}

\begin{abstract}
Özet
Amaç. Kronik obstruktif akciğer hastalı̆̆ yoğun psikolojik sıkıntılar yaşamasına neden olabilmektedir. Bu çalışmada, kronik obstruktif akciğer hastalığı olgularının yeti yitimi, anksiyete ve depresyon yönünden değerlendirilmesi amaçland. Böylece hastaların psikolojik yönden gereksinimlerinin belirlenebileceği ve bu durumun tedaviye katkısı olacağı düşünülmüştür. Yöntem. Çalışma kapsamında hastalara Kısa Yeti Yitimi Anketi ve Hastane Anksiyete Depresyon Ölçeği uygulandi. Bulgular. Araştırmaya 6 (\%24) kadın, 19 (\%76) erkekten oluşan toplam 25 kronik obstruktif akciğer hastalığı olan birey alındı. Yaş ortalamaları $68,44 \pm 12,38$ idi. Çalışmamızda, merkezimizde tedavi olan, kronik obstruktif akciğer hastalığılgularında; \%44 olguda anksiyete, \%68 olguda depresyon saptand. Ortalama Kısa Yeti Yitimi Anketi puanı 9,96olarak bulundu. Hafif yeti yitimi \%24 olguda, orta yeti yitimi \%32 olguda ve ağır yeti yitimi \%28 olguda saptandı. Sonuç. Sonuç olarak bu araştırma kronik obstruktif akciğer hastalığı olan bireylerin depresyon ve anksiyete gibi psikolojik problemlere eğilim gösterdiğini ve olguların büyük bölümünde yeti yitimi bulunduğunu ortaya koymuştur. Kronik obstruktif akciğer hastalığı kronik sistemik bir hastalık olarak düşünüldüğünde, eşlik eden psikolojik problemlerin kontrolü ve tedavisi de göz ardı edilmemelidir.
\end{abstract}

Anahtar sözcükler: Kronik obstrüktif akciğer hastalığı, anksiyete, depresyon, yeti yitimi

\begin{abstract}
Aim. Chronic obstructive pulmonary disease may lead to intense psychological distress as a result of the problems it cause in the lives of individuals. The aim of this study is to evaluate the chronic obstructive pulmonary disease patients in terms of disability, anxiety and depression. Thus, we thought that by this study psychological needs of patients can be determined and this condition can make a contribution to the treatment. Methods. Brief Disability Questionnaire and the Hospital Anxiety and Depression Scale was administered to a total of 25 [6 female (24\%) and 19 male (76\%)] patients with chronic obstructive pulmonary disease. Results. The mean age of the patients was $68.44 \pm 12.38$. In, Anxiety was found in $44 \%$ of patients while depression was detected in $68 \%$ of cases. The mean score of Brief Disability Questionnaire was found to be 9.96. Mild disability was in the $24 \%$ of patients, moderate disability was in $32 \%$ of cases and the severe disability was detected in the $28 \%$ of cases. Conclusion. Finally, this research revealed that the patients with chronic obstructive pulmonary disease tend to have psychological problems such as depression and anxiety.In addition, disability was present in the majority of cases.. As chronic obstructive pulmonary disease is considered to be a chronic systemic disease control and treatment of associated psychological problems should not be ignored.
\end{abstract}

Keywords: Chronic obstructive pulmonary disease, anxiety, depression, disability

Geliş tarihi/Received: 23 Ağustos 2012; Kabul tarihi/Accepted: 27 Ağustos 2012 


\section{*İletişim adresi:}

Dr. Bilgen Begüm Afşar, Göğüs Hastalıkları Kliniği, Uzun Mehmet Göğüs ve Meslek Hastalıkları Hastanesi, TR-67020 Zonguldak. E-posta: drbilgenbegum@yahoo.com

\section{Giriş}

KOAH tüm dünyada maluliyet ve ölümlerin önemli bir nedenidir [1]. KOAH, kronik fiziksel bir hastalık olmanın yanı sıra hasta açısından ruhsal, duygusal, sosyal, psikoseksüel bir dizi sorun ve çatışmanın gündeme gelmesine yol açabilen bir durumdur [2]. Beyin işlevlerini etkileyerek psikiyatrik bozukluklara yol açabileceği gibi hastalığın algılanması ve hastanın yaşam alanlarına etkisine bağlı olarak da psikiyatrik tablolar ortaya çıkabilir $[3,4]$. KOAH hastalarında başta depresyon ve anksiyete bozuklukları olmak üzere ruhsal bozuklukların genel populasyona oranla sik görüldüğü bildirilmektedir $[5,6]$. Tedavide belirtilere yönelik ilaç verilmesi yanında psikoterapötik yaklaşımların uygulanması önerilir. KOAH olan hastalarda depresyon yaygınlığı pek çok çalışmaya konu olmuştur.

$\mathrm{Bu}$ çalışmalarda, elde edilen oranlar, \%6-42 aralığındadır [5]. KOAH tanısı alanlarda depresif belirtilerin sıklıkla hastalığın görüntüsü gibi kabul edilmesi nedeniyle, depresyon nadiren tanınabilmekte ya da tedavi edilebilmektedir. KOAH'ta hipokseminin nörofizyolojik fonksiyonlarda değişikliklere yol açarak, depresyona eşlik ettiği gösterilmiştir [6]. Yeti yitimi, "bir etkinliği, kişi için normal kabul edilen sınırlarda veya biçimde yapabilme yetisinde, bir kısıtlanma ya da kayıp" olarak tanımlanmaktadır. Geçici ya da kalıcı olabilir [7]. Kronik hastalıklarda ruhsal bozukluklar ve buna bağlı yeti yitimi sağlıklı nüfusa kıyasla yüksek orandadır [4]. Çalışmamızda; Hastane Anksiyete Depresyon Ölçeği ve Kısa Yeti Yitimi Anketi kullanarak KOAH'lı olgularda, anksiyete, depresyon ve yeti yitimi durumunun belirlenmesi amaçlanmıştır.

\section{Gereç ve yöntem}

Süreyyapaşa Göğüs Hastalıkları ve Göğüs Cerrahisi Eğitim ve Araştırma Hastanesi'nde tedavi gören ve çalışmaya katılmayı kabul eden $25 \mathrm{KOAH}^{\prime} l 1$ olgu çalışmaya dahil edildi. Olguların tümü daha önceki yatışlarında veya poliklinik başvurularında öykü, fizik muayene, radyoloji ve solunum fonksiyon testi sonuçları ile Amerikan Göğüs Hastalıkları Topluluğu (American Thoracic Society) kriterlerine göre KOAH tanısı almış hastalardı. Çalışmadan dışlama ölçütleri; kooperasyon kurulamayan, Türkçe iletişim kuramayanlar, görüşme yapmayı ya da anketleri doldurmayı engelleyecek düzeyde bedensel hastalığı ya da bilişsel yetersizliği olanlar, halen psikiyatrik bir hastalık nedeniyle tedavi görenler, eşlik eden tedavi edilmemiş kalp veya böbrek hastalığı gibi hastalığı olanlar, genel durum bozukluğu olan hastalar olarak alındı. Hastanın standart medikal tedavisinin devam ediyor olmasına dikkat edildi. Uygulamaya başlanmadan önce hastalara KOAH'l hastaların yaşadıkları sıkıntılar ile ilgili araştırma yapıldığ 1 ve bu araştırmaya katılımın gönüllü olduğu bilgisi verilmiştir.

Çalışma için olgulardan sözlü ve yazılı onam alınarak hastalar için hazırlanmış onam formu imzalatıldı. Anketlerde yer alan sorular tüm hastalara araştırmacılardan birisi tarafindan (HIY) okunarak uygulanmıştır. Araştırmada veriler üç ayrı ölçek ile elde edilmiştir. Bunlar Sosyo-demografik Bilgi Formu, Hastane Anksiyete ve Depresyon Ölçeği, Kısa Yeti Yitimi Anketidir. Bu ölçekler hastanede yatan hastaların tedavisi tamamlandıktan sonra uygulanmıştır.

\section{Veri toplama yöntemi:}

1. Sosyo-demografik Bilgi Formu: Form benzer çalışmalar örnek alınarak çalışmacılar tarafından oluşturuldu. Bu formda hastaların yaş, cinsiyet, medeni hali, eğitim düzeyi, hastalık süresi gibi sosyo-demografik özelliklerini içeren yedi soru yer almaktadir. 
2. Hastane Anksiyete ve Depresyon (HAD) Ölçeği: Hastaların anksiyete ve depresyon düzeyini belirlemek amacıyla Hastane Anksiyete ve Depresyon Ölçeği (HAD) kullanılmıştır. HAD, Zigmoid ve Snaith [8] tarafından geliştirilmiş, bedensel hastalı̆̆ 1 olan ve birinci basamak sağlık hizmetine başvuran hastalarda anksiyete ve depresyon yönünden riski belirlemek, düzeyini ve şiddet değişimini ölçmek amacıyla uygulanan kendini değerlendirme ölçeğidir. Ölçeğin amacı tanı koymak değil, bedensel hastalığı olanlarda anksiyete ve depresyonu kısa sürede tarayarak risk grubunu belirlemektir. Ölçeğin ülkemiz için geçerlik ve güvenirlik çalışması Aydemir ve arkadaşları tarafından yapılmıştır. Ölçekteki soruların yedisi depresyon, yedisi anksiyete belirtilerini araştırır. Toplam 14 soru içermekte ve tek sayılar anksiyeteyi, çift sayılar depresyonu ölçmektedir. Yanıtlar dörtlü Likert biçiminde değerlendirilmektedir ve 0-3 arasında puanlanmaktadır. Anksiyete (HADA) ve depresyon (HAD-D) alt ölçekleri vardır. Türkiye'de yapılan çalışma sonucunda anksiyete alt ölçeği için kesme puanı 10/11 depresyon alt ölçeği için ise $7 / 8$ bulunmuştur. Buna göre, bu puanların üzerinde alanlar risk altında olarak değerlendirilir. Hastaların her iki alt ölçekten alabilecekleri en düşük puan 0 , en yüksek puan 21'dir.

3. Kısa Yeti yitimi Anketi-KYA (Brief Disabilty Questionnaire-BDQ): Dünya Sağlık Örgütü tarafından çalışmada kullanılmak üzere geliştirilen, bedensel ve sosyal yeti yitimini değerlendiren kısa bir ankettir. Genel Sağlı Taraması Kısa Formu'ndaki yeti yitimine ilişkin sorular temel alınarak geliştirilmiştir. Son bir aylık dönemin değerlendirildiği KYA'nde bedensel ve sosyal yeti yitimini soruşturan 11 soru bulunmaktadır. İlk sorular spor yapmak, masa çekmek, çanta taşımak, merdiven yokuş çıkmak, eğilmek, doğrulmak, ağır eşya kaldırmak, uzun mesafe yürümek, banyo yapmak, tuvalete gitmek gibi günlük uğraşların yerine getirilmesinde sağlık sorunları nedeniyle kişinin engellenip engellenmediği sorgulanmaktadır. Diğer sorular sağlık sorunlarının hobiler, günlük işler, çalışma isteği, iş verimi, kişiler arası ilişkileri üzerindeki etkilerini ölçmektedir [8]. Bu alanlardaki yeti yitimi, hasta tarafından 0 (hiç), 1 (bazen ya da biraz) veya 2 (her zaman ya da oldukça) olarak puanlandırılır. Puanların basitçe toplanması ile yeti yitimi toplam puanı elde edilmektedir. Toplam puan 0-22 arasında değişir. $(0-4=$ yeti yitimi yok), (5-7 = hafif yeti yitimi), $(8-12=$ orta ağırlıkta yeti yitimi), $(13$ puan ve üstü = ağır yeti yitimi) şeklinde değerlendirilmektedir. Türkçe'ye çevirisi, geçerlilik, güvenilirlik çalışmaları yapılmıştır [9].

\section{Bulgular}

Olguların 6'sı (\%24) kadın, 19'u (\%76) erkek ve yaş ortalamaları 68,44 $\pm 12,38$ 'dir. Olguların 18'i (\%72) evli, 7'si (\%28) bekar veya dul idi. Hastaların 6'sı (\%24) eğitimsiz, 16's1 (\%64) ilkokul ve ortaokul, 3'ü (\%12) lise ve üniversite eğitimi almışlardır. Olguların bireysel özellikleri tablo 1'de özetlenmiştir.

Tablo 1. Olguların bireysel özellikleri.

\begin{tabular}{llll}
\hline Özellikler & & n & \% \\
\hline Cinsiyet & Kadın & 6 & 24 \\
& Erkek & 19 & 76 \\
\hline Medeni durum & Evli & 18 & 72 \\
& Bekar - Dul & 7 & 28 \\
\hline Eğitim durumu & Eğitimsiz & 6 & 24 \\
& İlkokul - ortaokul mezunu & 16 & 64 \\
& Lise - üniversite mezunu & 3 & 12 \\
\hline Hastalık süresi & 5 yildan kısa & 7 & 28 \\
& 5 yildan uzun & 18 & 72 \\
\hline
\end{tabular}


KOAH olguların anksiyete puanı HAD ölçeğinin yedi anksiyete maddesine verilen cevapların toplanması ile elde edilmiştir. KOAH olgularının anksiyete puanlarının ortalamas1 $9 \pm 5,24$ (Min. $=0$, Maks. $=21)$ dir. KOAH olgularının depresyon puanları HAD ölçeğinin yedi depresyon maddesine verilen cevapların toplanması ile elde edilmiştir. Depresyon puanlarının ortalaması 9,44 \pm 3,9 $($ Min. $=0$, Maks. $=18)$ dur. KOAH olgularının genel psikolojik sıkıntı düzeyi HAD ölçeğinde yer alan 14 maddeye verilen cevaplar toplanarak elde edilmiştir. KOAH olgularının genel psikolojik sıkıntı puanının ortalamas1 18,44 \pm 4,63 (Min. $=0$, Maks. $=20)$ dir. Olguların depresyon ve anksiyete açısından eşik üstü / eşik altı puanlarına göre dağılımı tablo 2'de özetlenmiştir.

Tablo 2. Olguların depresyon ve anksiyete açısından eşik üstü / eşik altı puanlarına göre dağılımı.

\begin{tabular}{lll}
\hline Değişken & n & \% \\
\hline HAD Depresyon puanı & & \\
\hline Eşik altı (7 ve altında) & 8 & 32 \\
Eşik üstü (8 ve üzerinde) & 17 & 68 \\
\hline HAD Anksiyete puanı & & \\
\hline Eşik altı (10 ve altında) & 14 & 56 \\
Eşik üstü (11 ve üzerinde) & 11 & 44 \\
\hline
\end{tabular}

KOAH olgularına uygulanan kısa yeti yitimi anketi sonuçlarında en sık orta düzeyde yeti yitimi saptanmıştır. Olguların Kısa Yeti Yitimi Anketi sonuçlarına göre dağılımı tablo 3 'te özetlenmiştir.

Tablo 3. Olguların yeti yitimi derecelerinin dağılımı.

\begin{tabular}{lll}
\hline Yetiyitimi & n & \% \\
\hline Yok & 4 & 16 \\
Hafif & 6 & 24 \\
Orta & 8 & 32 \\
Ağır & 7 & 28 \\
\hline
\end{tabular}

Olguların bireysel özelliklerine göre anksiyete, depresyon dağılımı tablo 4'te özetlenmiştir.

Tablo 4. Hastaların demografik özelliklerine göre anksiyete, depresyon dağılımı.

\begin{tabular}{|c|c|c|c|c|c|c|c|c|}
\hline \multirow{3}{*}{ Özellikler } & \multicolumn{4}{|c|}{ Anksiyete } & \multicolumn{4}{|c|}{ Depresyon } \\
\hline & \multicolumn{2}{|c|}{ Eşik altı } & \multicolumn{2}{|c|}{ Eşik üstü } & \multicolumn{2}{|c|}{ Eşik altı } & \multicolumn{2}{|c|}{ Eşik üstü } \\
\hline & n & $\%$ & n & $\%$ & $\mathbf{n}$ & $\%$ & $\mathbf{n}$ & $\%$ \\
\hline \multicolumn{9}{|l|}{ Yaș } \\
\hline $15-29$ & 0 & $\%$ & 0 & $\%$ & 0 & $\%$ & 0 & $\%$ \\
\hline $30-59$ & 5 & $\% 62,5$ & 3 & $\% 37,5$ & 3 & $\% 37,5$ & 5 & $\% 62,5$ \\
\hline 60 ve üstü & 9 & $\% 52,9$ & 8 & $\% 47,1$ & 5 & $\% 29,4$ & 12 & $\% 70,6$ \\
\hline \multicolumn{9}{|l|}{ Cinsiyet } \\
\hline Kadın & 3 & $\% 50$ & 3 & $\% 50$ & 0 & $\% 0$ & 6 & $\% 100$ \\
\hline Erkek & 11 & $\% 57,9$ & 8 & $\% 42,1$ & 8 & $\% 42,1$ & 11 & $\% 57,9$ \\
\hline \multicolumn{9}{|l|}{ Medeni durum } \\
\hline Evli & 10 & $\% 55,5$ & 8 & $\% 44,4$ & 7 & $\% 38,9$ & 11 & $\% 61,1$ \\
\hline Bekar-Dul & 4 & $\% 57,1$ & 3 & $\% 42,8$ & 1 & $\% 14,3$ & 6 & $\% 85,7$ \\
\hline \multicolumn{9}{|l|}{ Eğitim durumu } \\
\hline Ĕgitimsiz & 4 & $\% 66,7$ & 2 & $\% 33,3$ & 2 & $\% 33,3$ & 4 & $\% 66,7$ \\
\hline İlkokul - ortaokul mezunu & 9 & $\% 56,2$ & 7 & $\% 43,7$ & 6 & $\% 37,5$ & 10 & $\% 62,5$ \\
\hline Lise - üniversite mezunu & 1 & $\% 33,3$ & 2 & $\% 66,6$ & 0 & $\% 0$ & 3 & $\% 100$ \\
\hline \multicolumn{9}{|l|}{ Hastalık süresi } \\
\hline 5 yıldan kisa & 4 & $\% 57,1$ & 3 & $\% 42,8$ & 2 & $\% 28,6$ & 5 & $\% 71,4$ \\
\hline 5 yildan uzun & 10 & $\% 55,5$ & 8 & $\% 44,4$ & 6 & $\% 33,3$ & 12 & $\% 66,7$ \\
\hline
\end{tabular}


Olguların bireysel özelliklerine göre yeti yitimi dağılımı tablo 5’te özetlenmiştir.

Tablo 5. Olguların demografik özelliklerine göre yeti yitimi dağılımı.

\begin{tabular}{|c|c|c|c|c|c|c|c|c|}
\hline \multirow{3}{*}{ Özellikler } & \multicolumn{8}{|c|}{ Yeti yitimi } \\
\hline & \multicolumn{2}{|c|}{ Yok } & \multicolumn{2}{|c|}{ Hafif } & \multicolumn{2}{|c|}{ Orta } & \multicolumn{2}{|c|}{ Ăğır } \\
\hline & n & $\%$ & n & $\%$ & n & $\%$ & & $\%$ \\
\hline \multicolumn{9}{|l|}{ Yaş } \\
\hline $15-29$ & 0 & $\% 0$ & 0 & $\% 0$ & 0 & $\% 0$ & 0 & $\% 0$ \\
\hline $30-59$ & 1 & $\% 12,5$ & 2 & $\% 25$ & 2 & $\% 25$ & 3 & $\% 37,5$ \\
\hline 60 ve üstü & 3 & $\% 17,6$ & 4 & $\% 23,5$ & 6 & $\% 35,3$ & 4 & $\% 23,5$ \\
\hline \multicolumn{9}{|l|}{ Cinsiyet } \\
\hline Kadın & 1 & $\% 16,7$ & 1 & $\% 16,7$ & 3 & $\% 50$ & 1 & $\% 16,7$ \\
\hline Erkek & 3 & $\% 15,8$ & 5 & $\% 26,3$ & 5 & $\% 26,3$ & 6 & $\% 31,6$ \\
\hline \multicolumn{9}{|l|}{ Medeni durum } \\
\hline Evli & 3 & $\% 16,7$ & 5 & $\% 27,8$ & 5 & $\% 27,8$ & 5 & $\% 27,8$ \\
\hline Bekar-Dul & 1 & $\% 14,3$ & 1 & $\% 14,3$ & 3 & $\% 42,8$ & & $\% 28,6$ \\
\hline \multicolumn{9}{|l|}{ Eğitim durumu } \\
\hline Eğitimsiz & 1 & $\% 16,7$ & 1 & $\% 16,7$ & 2 & $\% 33,3$ & 2 & $\% 33,3$ \\
\hline İlkokul - ortaokul mezunu & 2 & $\% 12,5$ & 5 & $\% 31,2$ & 4 & $\% 25$ & 5 & $\% 31,2$ \\
\hline Lise - üniversite mezunu & 1 & $\% 33,3$ & 0 & $\% 0$ & 2 & $\% 66,6$ & & $\% 0$ \\
\hline \multicolumn{9}{|l|}{ Hastalık süresi } \\
\hline 5 y1ldan k1sa & 1 & $\% 14,3$ & 2 & $\% 28,6$ & 2 & $\% 28,6$ & & $\% 28,6$ \\
\hline 5 y1ldan uzun & 3 & $\% 16,7$ & 4 & $\% 22,2$ & 6 & $\% 33,3$ & 5 & $\% 27,8$ \\
\hline
\end{tabular}

\section{Tartıșma}

KOAH tanısıyla izlenen hastaların oluşturduğu ve kesitsel özellik taşıyan çalışmamızda, psikiyatrik bir hastalık nedeniyle ilaç kullanmayan hastalarda, depresyon ve anksiyete düzeyleri ölçülmüş ve KOAH'lı olguların değerlendirme ölçekleri ile KOAH'lı olgularının \%44'ünde anksiyete, \%68'inde depresyon, \%24'ünde hafif yeti yitimi, \%32'sinde orta ve \%28'inde ağır yeti yitimi saptanmıştır. Çalışmalarda kronik bedensel hastalığı olanlarda ruhsal bozukluk oranları olmayanlara göre anlamlı düzeyde yüksek bildirilmiştir $[10,11]$.

KOAH'lı hastalarda anksiyete ve depresyon görülme s1klığı yüksektir [12-15]. Çeşitli çalışmalarda farklı yöntemler kullanılmakla beraber KOAH'l olgularda \% 6-42 arasında depresyon bildirilmektedir [5]. Yohannes ve ark. [16] 1998'de yaşlı KOAH olgularında, Kısa Depresyon Kartları Değerlendirme Yöntemi ile \%46 hastada depresyon saptadıklarını bildirmişlerdir. Bu oran aynı yaşta sağlıklı kişilerde \%11, yeti kaybına yol açan diğer hastalıklarda ise \%26 olarak saptanmıştır. Daha sonra aynı çalışma grubu bu yöntemle uyum bozukluğu olan hastalara da depresyon tanısı konabileceği olasıllğı nedeniyle 12-18 ay sonra tekrar aynı hasta grubunu incelemişler ve bu kez hastalara; hem Kısa Depresyon Kartları Değerlendirme (BASDEC), hem de geriatrik ruhsal durum ölçeği (AGECAT) kullanmışlardır. Bu çalışmada \%23 hastada depresyon, $\% 43$ hastada ise eşik altı anksiyete ve depresyon saptanmıştır [17]. Çelik ve ark. [12], KOAH'lı hastaların \%25'inde depresif bozukluk, \% 44,4'ünde psikojenik anksiyete saptamışlardır. Çalışmamıza katılan KOAH hastalarında saptadığımız anksiyete oranı yapılan diğer çalışmalar ile uyumlu bulundu. Aynı hastalarda depresyon oranı yapılan diğer çalışmalardan daha yüksek bulundu. Bunun nedeni çalışmamızın hastanede yatan hastalar ile yapılmış olması ve bu hastaların ileri evre KOAH olmalarından kaynaklanıyor olabilir.

Dünya Sağlık Örgütü ile yürütülen "Temel Sağlık Hizmetlerinde Ruhsal Sorunlar" isimli çalışmanın Gölbaşı (Türkiye) ayağında, ruhsal bozuklukların özellikle de depresyonun sosyal yeti yitimi ile ilişkili olduğu gösterilmiştir. Ruhsal bozukluğu olan hastalarda yeti yitimi, sadece kronik bedensel hastalığ bedensel hastalık ve ruhsal hastalık birlikteliğinde ise yeti yitimi daha da artmaktadır. 
Depresyonu olanların \%67,2'sinde yeti yitimi bulunmuştur [9]. Bu çalışmada HAD ölçeğine göre depresyonu ve anksiyetesi olan olgularda olmayanlara göre yaşam kalitesinin tüm alanlarında daha bozuk ve yeti yitiminin daha fazla olmas1, KOAH hastalarında depresyon-anksiyete düzeylerinin artmasının hastaların yaşam kalitelerini bozduğunu ve daha çok yeti yitimine yol açtığını gösterebilir.

Yapılan bir çalışmada yaş ile depresyon arasındaki ilişki incelenmiş, ortalamalar arasındaki fark istatistiksel olarak anlamlı bulunmuştur. İleri yaştaki hastaların depresyon düzeylerinin yüksek olduğu görülmektedir [18].

Bizim çalışmamızda 15-29 yaş arasında olgu bulunmamaktadır. Ancak 60 yaş üstü hastaların anksiyete ve depresyon düzeyleri yüksek saptanmıştır. Bulgularımız ileri yaş olgularında depresyonun ve anksiyetenin daha fazla görüldüğünü bildiren yayınlarla uyumludur.

Çalışmamızda kadın hastalarda erkek hastalara göre sosyal fonksiyon dışındaki tüm alanlarda yaşam kalitesi puanlarının daha düşük; orta-ağır düzeyde yeti yitiminin daha fazla olduğu görülmektedir. Kadınlarda daha fazla depresyon ve anksiyete görüldüğü bildirilmektedir [19]. Çalışmamızda, kadın olgu sayısı az olmakla birlikte hepsinde depresyon saptanmıştır. Bunun nedeninin kadınların anne, eş, ev kadını, iş kadını gibi pek çok rolü aynı anda üstlenmek zorunda kalmaları nedeniyle daha fazla strese maruz kalmaları ve gelecek kaygısının daha fazla olması olabilir [20, 21].

Bazı çalışmalarda eğitim düzeyi arttıkça anksiyete ve depresyon düzeylerinin azaldığ 1 saptanırken bazılarında ise eğitim durumu ile anksiyete ve depresyon düzeyleri arasında ilişki saptanmamıştır [18, 20-25]. Bu çalışmada eğitim düzeyi arttıkça anksiyete ve depresyon düzeylerinin arttığ 1 , yeti yitiminin ise azaldığ görülmektedir. Bu durum bizim örneklem grubumuzun az sayıda olgudan oluşmasının yanı sıra gruplar arasında, KOAH açısından, hastalık şiddeti değerlendirilmesinin yapılmamış olmasından da kaynaklanmış olabilir.

Yaşam kalitesi bozukluğu enerji, hareketlilik, uyku azalması, emosyonel fonksiyon, depresyon, anksiyete, yaşamda tatminsizlik ve somatik meşguliyet şeklinde yansitılır [26]. Egzersiz kısıtlaması yaşam kalitesini azaltan en önemli faktördür [27]. KOAH'ın ciddi fiziksel ve psikososyal yetmezlikler oluşturması sonucu olgularda; hayat tarzında değişiklik, kısıtlılık, umutsuzluk, öfke, irritabilite, saldırganlık, güvensizlik, mesleki, sosyal ve seksüel yetmezlikleri yanı sira depresyon, anksiyete bozukluğu, alkolizm, paranoya, distimik bozukluk, hipokondriazis gibi mental bozukluklar tabloya eşlik edebilir. Ayrıca yapılan çalışmaların çoğu; nefes darlığı, hipoksi ve emosyonel bozuklukların bir arada görüldüğünü ortaya koymuştur [28]. Yapılan çalışmalarda pulmoner rehabilitasyon sonrası olguların egzersiz toleransında, yaşam kalitesinde, anksiyete ve depresyon düzeylerinde anlamlı gelişmeler gözlenmiştir [29].

Çalışmamızda kontrol grubunun olmayışı, olguların ek hastalıklarının bilinmemesi, olgu sayısının az olması yanı sıra tıbbi hastalıklarının şiddetinin değerlendirilmemiş olması ve tanı koydurucu psikiyatrik görüşmelerin yapılmamış olması çalışmayı kısıtlayan faktörler olarak değerlendirilebilir.

Sonuç olarak bu araştırma KOAH'lı olguların depresyon ve anksiyete gibi psikolojik problemlere eğilim gösterdiğini ve olguların büyük bölümünde yeti yitimi bulunduğunu ortaya koymuştur. KOAH kronik sistemik bir hastalık olarak düşünüldüğünde, eşlik eden psikolojik problemlerin kontrolü ve tedavisi de göz ardı edilmemelidir. 


\section{Kaynaklar}

1. Global Initiative for Chronic Obstructive Lung Disease, executive summary 2003. www.goldcopd.com (Erişim tarihi: 31.08.2012)

2. Taytard A, Cousson F. Symptoms and life of patients with chronic bronchitis. Preliminary results. Rev Pneumol Clin 1996; 52: 379-85.

3. Seemungal TA, Donaldson GC, Paul EA, Bestall JC, Jeffries DJ, Wedzicha JA. Effect of exacerbation on quality of life in patients with chronic obstructive pulmonary disease. Am J Respir Crit Care Med 1998; 157: 1418-22.

4. Garcia-Aymerich J, Farrero E, Félez MA, Izquierdo J, Marrades RM, Antó JM; Estudi del Factors de Risc d'Agudització de la MPOC investigators. Risk factors of readmission to hospital for a COPD exacerbation: a prospective study. Thorax 2003; 58: 100-5.

5. van Ede L, Yzermans CJ, Brouwer HJ. Prevalence of depression in patients with chronic obstructive pulmonary disease: a systematic review. Thorax 1999; 54: 688-92.

6. McSweeney AJ, Heaton RK, Grant I, Cugell D, Solliday N, Timms R. Chronic obstructive pulmonary disease; socioemotional adjustment and life quality. Chest 1980; 77: 309-11.

7. World Healt Organization. International Classification of Impairments, Disabilities and Handicaps: a Manuel of Classification Relating to the Consequences of Disease. WHO 1980, Cenevre.

8. Aydemir Ö, Köroğlu E. Psikiyatride Kullanılan Klinik Ölçekler. Ankara: Hekimler Yayın Birliği, 2000.

9. Kaplan İ. Yarı kırsal alanda bir sağlık ocağına başvuran hastalarda ruhsal bozuklukların yeti yitimi ile ilişkisi. Türk Psikiyatri Dergisi 1995; 6: 169-79.

10. Wells KB, Golding JM, Burnam MA. Psychiatric disorder and limitations in physical functioning in a sample of the Los Angeles general population. Am J Psychiatry 1988; 145: 712-7.

11. Üçok GÖ. Bir sağlı ocağına başvuran hastalarda bedensel ve ruhsal hastalığın birlikte bulunuşu. Türk Psikiyatri Dergisi 1995; 6: 180-5.

12. Çelik P, Esen A, Akın M, İçelli İ, Yorgancıoğlu A. Kronik obstrüktif akciğer olgularında depresyon. Solunum Hastalıkları 1998; 9: 25-32.

13. Kömürcüoğlu B, Balığlu M, Öztuna I, Büyükşirin M, Işık E, Perim K. KOAH’ 11 erkek olgularda depresyon. Toraks Dergisi 2000; 1: 31-4.

14. Dahlen I, Jansob C. Anxiety and depression are related to the outcome of emergency treatment in patients with obstructive pulmonary disease. Chest 2000; 122: 1633-7.

15. Dowson CA, Town GI, Frampton C, Mulder RT. Psychopathology and illness beliefs influence COPD self-management. J Psychosom Res 2004; 56: 333-40.

16. Yohannes AM, Roomi J, Waters K, Connolly MJ. Quality of life in elderly patients with COPD: measurement and predictive factors. Respir Med 1998; 92: 1231-6.

17. Thornton A, Yohannes AM, Baldwin RC, Connolly MJ. Chronic obstructive pulmonary disease and depression: analysis of depressive symptoms. Age Ageing 2000; 29: 286-7.

18. Bahar A, Savaşı HA, Parlar S. Göğüs Hastalıkları Servisinde yatan hastaların anksiyete ve depresyon düzeylerinin belirlenmesi. Yeni Symposium Journal 2009; 47: 9-15.

19. Özer SK, Demir B, Tuğal Ö Kabakçı E, Yazıcı MK. Montgomery-Asberg Depresyon Değerlendirme Ölçeği: Değerlendiriciler Arası Güvenilirlik ve Geçerlik Çalışması. Türk Psikiyatri Dergisi 2001; 12: 185-94.

20. Atacanlı MF, Dilbaz N. Kronik obstrüktif akciğer hastalığı ve depresyon. Klinik Psikiyatri 2001; 4: 147-53.

21. Yetişkin Ş. Hemodiyaliz Hastalarının Yeti Yitimi, Anksiyete ve Depresyon 
Yönünden Değerlendirilmesi. Sağlık Bakanlığı İstanbul Eğitim ve Araştırma Hastanesi Aile Hekimliği Uzmanlık Tezi. İstanbul, 2008.

22. Üskül TB, Selvi A, Melikoğlu A, Varol N, Türker H. Göğüs hastalıkları kliniğinde yatan hastalarda anksiyete ve depresyon düzeyleri ile sosyodemografik faktörlerin ve hastalık tanılarının ilişkisi. Akciğer Arşivi 2006; 7: 11-5.

23. Yakar T, Baran A, Güngör S, Altinsoy B, Yalçinsoy M, Can G, Akkaya E. Astımlı hastalarda beck depresyon ölçeğini etkileyen faktörler. Tuberk Toraks 2007; 55: 11-7.

24. Atagöz K. KOAH olan hastaların yasam kalitelerinin incelenmesi (tez), İzmir: 1998 D.Ü Sağlık Bilimleri Enstitüsü. Danışman: Doç. Dr. G.Başer

25. Acar N. KOAH'lı Hastalarda Tedaviyi Etkileyen Faktörlerin İncelenmesi (tez). İstanbul: M.Ü. Sağlık Bilimleri Enstitüsü Yüksek Lisan Tezi; 2002.

26. Guyatt GH, Townsend M, Berman LB, Pugsley SO. Quality of life in patients with chronic airflow limitation. Br J Dis Chest 1987; 81: 45-54.

27. Akbay S, Kurt B, Ertürk A, Gülhan M, Çapan N. Kronik Obstruktif Akciğer Hastalığında Yaşam Kalitesi ve Solunum Fonksiyon Testi ile İlişkisi. Tüberküloz ve Toraks Dergisi 2001; 49: 338-44.

28. Baştürk M, Eşel E. Kronik Obstruktif Akciğer Hastalığı Olanlarda Mental Bozukluklar. Erciyes Tip Dergisi 1993; 15: 307-15.

29. Garuti G, Cilione C, Dell'Orso D, Gorini P, Lorenzi MC, Totaro L, Cirelli G, Clini E. I mpact of comprehensive pulmonary rehabilitation on anxiety and depression in hospitalized COPD patients. Monaldi Arch Chest Dis 2003; 59: 5661. 